\title{
Microphysical process of precipitating hydrometeors from warm- front mid-level stratiform clouds revealed by ground-based lidar observations
}

5 Yang $\mathrm{Yi}^{1,2,3}$, Fan $\mathrm{Yi}^{1,2,3,{ }^{*}}$, Fuchao Liu ${ }^{1,2,3}$, Yunpeng Zhang ${ }^{1,2,3}$,Changming $\mathrm{Yu}^{1,2,3}$, and $\mathrm{Yun} \mathrm{He}^{1,2,3}$

${ }^{1}$ School of Electronic Information, Wuhan University, Wuhan 430072, China

10

${ }^{2}$ Key Laboratory of Geospace Environment and Geodesy, Ministry of Education, Wuhan 430072, China

${ }^{3}$ State Observatory for Atmospheric Remote Sensing, Wuhan430072, China

Correspondence to: Fan Yi (yf@whu.edu.cn)

\section{Abstract}

15 Mid-level stratiform precipitations during the passage of warm front were detailedly observed on two occasions (light and moderate rain) by a 355-nm polarization lidar and water-vapor Raman lidar, both equipped with waterproof transparent roof windows. The hours-long precipitation streaks shown in the lidar signal $(X)$ and volume depolarization ratio $\left(\delta_{\mathrm{v}}\right)$ reveal some ubiquitous features of the microphysical process of precipitating hydrometeors. We find that for the light rain case, surface rainfall begins as supercooled liquid-drop-dominated hydrometeors fall out of their liquid parent cloud at altitudes above the $0{ }^{\circ} \mathrm{C}$ level, and most liquid drops quickly freeze into ice particles $\left(\delta_{\mathrm{v}}>0.25\right)$ during the first $100-200 \mathrm{~m}$ of their descent, where humid aerosol particles exist. Subsequently, the falling hydrometeors yield a dense layer with an ice/snow bright band occurring above and a liquid-water bright band occurring below (separated by a lidar dark band) as a result of crossing the 0 ${ }^{\circ} \mathrm{C}$ level. The ice/snow bright band might be a manifestation of local hydrometeor accumulation. Most falling raindrops shrink or vanish in the liquid-water bright band due to evaporation, whereas a few large raindrops fall out of the layer. We also find that a prominent $\delta_{\mathrm{v}}$ peak $(0.10-0.35)$ always occurs at an altitude of approximately $0.6 \mathrm{~km}$ during surface rainfall, reflecting the collision-coalescence growth of falling large raindrops and their subsequent spontaneous breakup. The microphysical process (at ice-bright-band altitudes and below) of moderate rain resembles that of the light rain case, but more large-sized hydrometeors are involved. 


\section{Introduction}

An observation-based understanding of the microphysical processes of precipitation is essential for weather/climate modeling and predictions. Such processes are difficult to observe since they involve a variety of hydrometeor sizes, shapes and phases at different altitudes, all of which are affected by cloud dynamics (Aggarwal et al., 2016; Pfitzenmaier et al., 2018). In situ aircraft observations deliver data on the sizes and numbers of hydrometeors only for small sampling volumes at single altitudes at any given time during preplanned case studies (Barrett et al., 2019). Although lidar and radar can measure the time-resolved vertical profiles of bulk backscattering quantities, retrievals of the microphysical properties of hydrometeors requires numerous assumptions (e.g., the hydrometeor shape and size distributions). Furthermore, in most cases, ground-based lidar cannot penetrate high enough to sample complete precipitating hydrometeor layers (only profiling the lower part of a layer) due to signal attenuation. Thus information about their parent clouds is usually not available (Sassen et al., 2005; Di Girolamo et al., 2012; Mega et al., 2012). There is also a lack of systematically observed lidar data on precipitation processes because most lidar systems are not protected from precipitation. Cloud/precipitation radars are insensitive to small raindrops and droplets in cloud layers. Therefore, the microphysical processes of precipitation formation are not well understood thus far.

Satellite observations have revealed that cold clouds are the major source of liquid precipitation over land (Mülmenstädt et al., 2015). Heterogeneous ice formation pertinent to cold clouds is believed to lead to the generation of rain (Field and Heymsfield 2015; Bühl et al., 2016; Pfitzenmaier et al., 2018). The ice formation process has been studied extensively by observing liquid-layer-topped ice virgae because ground-based lidar and radar can reliably sample the entire height ranges of 50 ice virgae and their parent cloud bases (Ansmann et al., 2009; de Boer et al., 2011; Bühl et al., 2016; Bühl et al., 2019). In stratiform cloud layers at temperatures above $-20{ }^{\circ} \mathrm{C}$, precipitating bulk ice particles (ice virga) occurred after bulk liquid phases had formed overhead (Ansmann et al., 2009; de Boer et al., 2011). This suggests that the heterogeneous nucleation of ice proceed via the freezing of supercooled droplets (Ansmann et al., 2009; de Boer et al., 2011). Our polarization lidar observations have revealed the detailed vertical structures of falling mixed-phase virgae and their supercooled liquid parent cloud layers, suggesting that most supercooled liquid drops falling out of parent clouds rapidly froze into ice crystals on the tops of virgae where there usually existed humid aerosol layers (Cheng and Yi, 2020).

To study the microphysical processes that occur at altitudes ranging from the parent cloud base down to the near-surface during surface precipitation, a 355-nm polarization lidar and a water vapor Raman lidar at the Wuhan University atmospheric observation site were equipped with waterproof transparent roof windows. An artificial water splashing experiment was performed on the roof windows to examine the effects of water accumulation. Water accumulation on the 
lidar roof windows yielded only height-independent lidar signal ( $X$, range-corrected signal) attenuation, whereas neither the $X$ vertical structure nor the profile of the volume depolarization ratio $\delta_{v}$ (the magnitude and vertical structure) were altered. In addition, water accumulation on the roof windows hardly impacted the lidar-observed subcloud water vapor mixing ratio $65\left(q_{v}\right)$ profiles. This allows us to systematically observe precipitation processes (light and moderate rains). Based on our lidar observations obtained on two warm front occasions, a complete microphysical process is revealed for precipitating hydrometeors pertinent to warm-front-related mid-level stratiform precipitation. This paper first depicts the relevant instrumentation and methodology. Section 3 presents two light and moderate warm-front precipitation cases observed at our lidar site. The summary and conclusions are given in section 4 .

\section{Instrumentation and Methodology}

\subsection{Lidar}

Precipitating hydrometeor observations were obtained with two newly developed lidars equipped with waterproof transparent roof windows at the Wuhan University atmospheric observatory $\left(30.5^{\circ} \mathrm{N}, 114.4^{\circ} \mathrm{E}, 73 \mathrm{~m}\right.$ above sea level). The roof windows were designed to project out from the surroundings, avoiding a heavy water accumulation on the window glass during rainfall. The two lidars can simultaneously deliver the sequential profiles of the range-corrected signal $X$, volume depolarization ratio $\delta_{v}$ and water vapor mixing ratio $q_{v}$. All the observation sessions started with clear-sky conditions and ended when heavy precipitation occurred. This allowed us to capture the evolving layer structures of light and moderate precipitation events as well as their precursor clouds present over our mid-latitude site.

\subsubsection{Polarization Lidar}

The polarization lidar has a configuration similar to our 532-nm system (Kong and Yi, 2015), but the transmitter employs a frequency-tripled $\mathrm{Nd}$ :YAG laser. It produces emissions of $\sim 150 \mathrm{~mJ}$ per pulse at $355 \mathrm{~nm}$ with a repetition rate of $30 \mathrm{~Hz}$. A Brewster polarizer is added to improve the polarization purity of the transmitting laser (up to 10000:1). After beam expansion, the beam with a divergence of $0.15 \mathrm{mrad}$ is transmitted vertically into the atmosphere. The backscattered light is collected by a 20 -cm Cassegrain telescope. The field of view (FOV) of the receiver is $\sim 1 \mathrm{mrad}$. After collimation, the elastically backscattered light passes an interference filter (with a $0.3-\mathrm{nm}$ bandwidth centered at $355 \mathrm{~nm}$ ) and then incidents a polarization beam splitter prism (PBS). To decrease the cross talk between the two orthogonal polarization channels, two additional polarizers are placed on the two output sides of the PBS. The light exiting from the two polarizers is focused onto two photomultiplier tubes (PMTs). The signals from the two PMTs are gathered by a PC-controlled two-channel transient digitizer (TR40-160, manufactured by Licel). 
The raw lidar data are stored in both analog and photon counting modes with a range resolution of $3.75 \mathrm{~m}$ and a temporal resolution of $1 \mathrm{~min}$. Based on a method developed by Newsom et al. (Newsom et al., 2009; Zhang et al., 2014), the stored analog and photon-count data are glued to form a reasonable photon-count profile with a large dynamic range. The range and temporal resolution of the glued photon count profiles are $30 \mathrm{~m}$ and $1 \mathrm{~min}$, respectively. The starting altitude of the lidar measurements is $\sim 0.3 \mathrm{~km}$, determined based on the overlap of the laser and the field of view of the telescope. The altitude values referenced in this article are all relative to sea level.

The range-corrected lidar signal $X$ is utilized to represent the backscattering intensity (returned laser power) of cloud particles and gravitationally-falling hydrometeors (Ansmann et al., 2008). The volume depolarization ratio $\delta_{v}$, defined by the ratio of the perpendicular- to parallel-polarized backscatter coefficients, can be obtained from the two-channel lidar signals along with the relative gain of the parallel and perpendicular channels. The relative gain is determined in advance using a conventional method (Freudenthaler et al, 2009). The magnitude of the $\delta_{v}$ value allows us to identify whether the dominant backscattering is attributed to ice crystals or water droplets in a given backscatter volume (Shupe, 2007). Liquid water droplets suspended in the atmosphere are nearly spherical and produce a very low depolarization ratio (close to zero) for single scattering at exactly $180^{\circ}$, while ice crystals, which are usually nonspherical, generate a quite large depolarization ratio in the $180^{\circ}$ backscattering direction. In this precipitation study, the persistently observed lidar dark band (the snowflake-to-raindrop transition just below the $0{ }^{\circ} \mathrm{C}$ isotherm level) can be used to differentiate between the altitudinal regions with ice-containing particles above the dark band and liquid raindrops below the dark band. Hence, at altitudes above the dark band, the discrimination criteria in terms of the depolarization ratio magnitude are $\delta_{v}<0.1$ for water droplets/drops

110 and $\delta_{v}>0.2$ for ice crystals (Intrieri et al., JGR, 2002; Shupe et al., JGR, 2008), while an enhanced depolarization ratio $\left(\delta_{v}>\right.$ 0.1 ) at altitudes below the dark band indicates the presence of large raindrops. An artificial water splashing experiment was performed on the lidar roof windows to examine the effects of water accumulation. Water accumulation on the lidar roof windows yielded only height-independent lidar signal $(X)$ attenuation, and neither the $X$ vertical structure nor the profile of the volume depolarization ratio $\delta_{v}$ (the magnitude and vertical structure) were altered. This result is physically reasonable.

\subsubsection{Water Vapor Raman Lidar}

The configuration of the water vapor Raman lidar used in this study is similar to our 45-cm-aperture Raman system (Wu and Yi, 2017), but the current Raman lidar shares the same transmitter with our 355-nm polarization lidar depicted above. It detects inelastic Raman backscatter from water vapor at $407 \mathrm{~nm}$ and nitrogen molecules at $387 \mathrm{~nm}$ as well as detecting elastic backscattered light by using a 20 -cm receiver telescope. The water vapor mixing ratio $q_{v}$, which is defined as the mass ratio between water vapor and dry air in a given volume, can be obtained from the Raman signals representing water vapor and nitrogen molecules (Whiteman et al., 1992). The Raman lidar system was calibrated by corresponding local radiosonde measurements. A comparison showed that the lidar-derived water vapor mixing ratio profiles agree well with the coincident radiosonde data (the relative deviation is less than $10 \%$ when the water vapor field is horizontally homogeneous on a scale of 

light, so the water vapor mixing ratio profiles are available only at altitudes below $\sim 2 \mathrm{~km}$. A similar artificial water-splashing experiment to that described above was performed on the water vapor Raman lidar roof window. Water accumulation on the roof window hardly has an impact on the obtained subcloud $q_{v}$ profiles.

\subsection{Radiosonde}

The radiosondes are launched at 0800 LT (0000 UTC) and 2000 LT (1200 UTC) every day from the Wuhan weather station

130 ( $\sim 23.4 \mathrm{~km}$ away from our lidar site). Profiles of the air pressure, temperature, relative humidity, wind speed, and direction from the near surface up to a height of 20-30 km are measured. The obtained radiosonde profiles are used to quantitatively determine the meteorological conditions pertinent to the precipitation events and their precursor clouds. The temperature measurement error is less than $1^{\circ} \mathrm{C}$, and the uncertainty in the relative humidity measurement is less than $5 \%$ when the temperature is higher than $10^{\circ} \mathrm{C}(\mathrm{Nash}, 2011)$.

\subsection{All-sky camera and rain gauge}

The cloud photographs are recorded every two minutes by a ground-based all-sky camera located at our lidar site. A tippingbucket rain gauge is used to measure the precipitation rate at the surface.

\section{Observational Results}

\subsection{Light warm-front precipitation (26-28 December 2017)}

140 Figure 1 presents an example of lidar observations obtained during a warm front passage and the resulting light precipitation. As seen from Figs. 1a and 1b, a varying cloud layer descended steadily from $\sim 10.3 \mathrm{~km}$ at $\sim 1600$ LT on 26 December to $\sim 3.0$ $\mathrm{km}$ at approximately $2351 \mathrm{LT}$ on 27 December 2017. The cloud layer was mostly characterized by a mixed phase and had subcloud ice virgae during the later descent (Figs. 1a and 1b). After the subcloud virgae reached an altitude $(\sim 3.0 \mathrm{~km})$ that was lower than the $0{ }^{\circ} \mathrm{C}$ level $(\sim 3.6 \mathrm{~km})$, as measured by a conventional radiosonde at approximately $2000 \mathrm{LT}$ on 27 December at the Wuhan weather station ( $23 \mathrm{~km}$ away from our lidar site), falling raindrops (precipitation streaks in the $X$ and $\delta_{v}$ contour plots) that reached the ground were frequently observed beneath the 3-km altitude until 0536 LT on 28 December 2017 when the lidar operation terminated. The associated water vapor mixing ratio, $q_{v}$, increased steadily with the descent of the cloud layers (Figure 1c). In particular, a high-concentration moisture layer appeared in the subcloud region during the rainfall event. This moisture layer resulted mainly from the evaporation of snow/ice particles and raindrops.

150 Corresponding photographs of the sky taken by a ground-based camera at our lidar site are given at the top of Fig 1 . The light rain lasted for $\sim 8 \mathrm{~h}$ and yielded an accumulated surface rainfall amount of $2.6 \mathrm{~mm}$ (rain gauge data obtained at our lidar 
site). Interestingly, a humid aerosol layer also moved downward from $\sim 4.2 \mathrm{~km}$ at $\sim 2000 \mathrm{LT}$ on 25 December to $\sim 2.3 \mathrm{~km}$ at 2000 LT on 27 December 2017, which appeared to be associated with the warm front.

\subsubsection{Associated meteorological conditions}

Figure 2 presents the radiosonde profiles that are pertinent to the precursor clouds of the light warm-front precipitation event, together with the 1-h mean lidar profiles obtained during the radiosonde launches. A downgoing moist layer was observed strengthening and broadening with time between 2000 LT on 26 December and 2000 LT on 27 December 2017 (Figs. $2 \mathrm{~b}$ and 2c). Correspondingly, the descending cloud layers changed from intermittent cirrus (photo I in Figure 1) and altocumulus (photo II) to altostratus with drizzle (photo III). The intermittent cirrus resided at altitudes of 9.5-10.7 km at approximately 2000 LT on 26 December. A strong southwesterly wind prevailed in this altitude range (Figure 2f, blue). The in-cloud air had relative humidities over water from 32 to $70 \%$ (Figure $2 \mathrm{~b}$, blue), suggesting that the cirrus was far away from the region of its formation. At the same time, a humid aerosol layer lay at an altitude of approximately $\sim 3.6 \mathrm{~km}$ (Figs. 2c and $2 \mathrm{~d}$, blue). The temperature and relative humidity of this layer over water were $-3.9^{\circ} \mathrm{C}$ and $96 \%$, respectively, around the layer peak. At approximately 0800 LT on 27 December 2017, the virgae at the bottom of the descending cloud layer reached an altitude of $\sim 6.6 \mathrm{~km}$ (Figs. $2 \mathrm{~d}$ and $2 \mathrm{e}$, green). The altocumulus was advected from the southwest, as shown in the wind component profiles (Figure 2f, green). The accompanying moisture layer dropped to altitudes ranging from $\sim 6.6-10.5 \mathrm{~km}$ (Figs. $2 \mathrm{~b}$ and 2c) with increased relative humidities over water of $41-83 \%$. In the upper part (8.4-10.5-km altitudes) of the layer, the air within the temperature range of $-26^{\circ} \mathrm{C}$ to $-34{ }^{\circ} \mathrm{C}$ was slightly supersaturated with ice. The moist aerosol layer moved down to an altitude of $\sim 3.2 \mathrm{~km}$, where the relative humidity over water was $\sim 75 \%$ and the temperature was $-1.5^{\circ} \mathrm{C}$. At $\sim 2000 \mathrm{LT}$ on 27 December, the descending moist layer extended from 4.0 to $10.9 \mathrm{~km}$ with increased relative humidities over water of $77-94 \%$ (Figure $2 b$, orange). The descending parent cloud layer and ice virgae below the cloud layer both resided within the moist layer (Figures $2 \mathrm{~d}$ and 2e, orange). According to the radiosonde moisture profile, the parent cloud layer was present at altitudes ranging from $\sim 4.7$ to $10.7 \mathrm{~km}$ where the air was supersaturated with ice, with relative humidities over ice of $\sim 100$ $120 \%$ at temperatures between $-8.8{ }^{\circ} \mathrm{C}$ and $-44{ }^{\circ} \mathrm{C}$ (Figure 2a, orange). The high cloud top height $(10.7 \mathrm{~km})$ required a strong updraft. In this scenario, the parent cloud should have a multilayer structure. The southwesterly wind dominated over most of the altitude range of the moist layer (Figure 2f, orange). As seen in Figure $2 \mathrm{~d}$ (orange), the humid aerosol layer reached altitudes from 2.2-3.3 km with a maximum relative humidity over water of $85 \%$ at an altitude of $2.8 \mathrm{~km}$. Aerosol layer-related moisture was incorporated into the descending moist layer.

The radiosonde released at 0800 LT on 28 December 2017 provided measurements of the meteorological conditions during the surface rainfall, although the lidar measurements had already terminated (at 0538 LT) $\sim 2$ hours earlier. As seen from Figure $2 \mathrm{~b}$ (red), the moisture layer ranged from $\sim 1.8$ to $7.8 \mathrm{~km}$ in altitude with enhanced relative humidities over water of $82-98 \%$. In particular, the relative humidity reached a maximum of $98 \%$ with respect to water in an altitude range of $\sim 3-4$ 
$\mathrm{km}$, immediately above the tops of the liquid precipitation streaks (at $\sim 3 \mathrm{~km}$, see Figs. 1a and $1 \mathrm{~b}$ ). Water vapor at altitudes of $3.0-7.8 \mathrm{~km}$ was advected from the southwest, as seen in the wind component profiles (Figure $2 \mathrm{f}$, red). The high water vapor mixing ratios observed at altitudes below $\sim 3 \mathrm{~km}$ came from the evaporation of falling raindrops.

\subsubsection{Microphysical process of precipitating hydrometeors for the light warm-front rain}

The $X$ and $\delta_{v}$ precipitation streaks were visible in the period between 2351 LT on 27 December and 0536 LT on 28 December 2017 (Figs. 1a and 1b). The streaks extended from the starting height ( 0.3 km) of the lidar measurements to an altitude of $\sim 2.88 \mathrm{~km}$ when surface precipitation occurred. A lidar dark band ( $X$ minimum) appeared persistently on the top of the precipitation streaks at an $\sim 2.88$-km altitude except when the dark band was concealed by a drifting small-scale cloud (at 2.2-2.6-km altitudes during 0418-0536 LT on 28 December). This is consistent with earlier lidar observations of stratiform precipitation (Sassen and Chen, 1995; Demoz et al., 2000; Roy and Bissonnette, 2001; Di Girolamo et al., 2012). An inapparent local depolarization $\left(\delta_{v}\right)$ minimum was also persistently present at an altitude of $\sim 2.76 \mathrm{~km}$, lying just $\sim 100 \mathrm{~m}$ below the dark-band minimum (Figure 1b). The local $\delta_{v}$ minimum represented the completion of the melting process of most falling ice/snow particles. Note that the $\delta_{v}$ value decreased as a whole from the ice/snow (including partially melted large particles) values $(0.10-0.34)$ at altitudes above the lidar dark band to the small liquid drop level $(\leq 0.04)$ at an altitude $\sim 100$ $\mathrm{m}$ below the dark-band minimum. The lidar dark band definitely differentiates the altitude regions of precipitating icecontaining hydrometeors occurring above and liquid raindrops occurring below. Although the rainfall-induced water accumulation on the roof window of the lidar varied with time, the precipitation streaks and dark band were steadily reasonably displayed in the $X$ and $\delta_{v}$ time-height plots (Figures 1a and 1b). This is consistent with the result of our water splashing experiment in which the water accumulation on the roof windows of the lidars only yielded height-independent lidar signal $(X)$ attenuation, whereas neither the $X$ vertical structure nor the magnitude or vertical structure of the depolarization ratio $\delta_{v}$ were altered.

To further clarify the microphysical process of precipitating hydrometeors, two sets of representative lidar profiles $\left(X, \delta_{v}\right.$ and $q_{v}$ ) for the surface rainfall period shown in Figure 1 are plotted in Figs. 3 and 4. Figure 3 gives three 1-min $X$ and $\delta_{v}$ profiles from 0112 to 0114 LT on 28 December 2017 and a one-hour-averaged $q_{v}$ profile centered at 0113 LT on the same day. The lidar dark band appeared at a $2.88-\mathrm{km}$ altitude at approximately $0113 \mathrm{LT}$, while the local $\delta_{v}$ minimum $(<0.04)$ was located at

210 a $2.76-\mathrm{km}$ altitude. These altitudes represent a typical lidar signature of the snowflake-to-raindrop transition for a variety of stratiform precipitation events initiating at altitudes more than $1 \mathrm{~km}$ above the $0{ }^{\circ} \mathrm{C}$ isotherm level. An ice-containing bright band (ice bright band hereafter) with $\delta_{v}$ values ranging from $\sim 0.13$ to $\sim 0.39$ was visible at altitudes $\sim 3.0-3.45 \mathrm{~km}$, just above the lidar dark band (Figure 3); these altitudes correspond to the "relative lidar bright band" in the literatures (Sassen and Chen, 1995; Di Girolamo et al., 2012). The ice bright band peaked on its bottom ( 3.0 km). The ice bright band showed a variable vertical structure and intensity (in both $X$ and $\delta_{v}$ ) on the time scale of minutes, representing the presence of small- 
scale fluctuations in the precipitating ice crystals and snowflakes. A liquid water bright band arose at $\sim 1.50-2.76-\mathrm{km}$ altitudes just below the lidar dark band (Figure 3), which is designated the "weak lidar bright band" in the literatures (Sassen and Chen, 1995; Di Girolamo et al., 2012). The $\delta_{\mathrm{v}}$ values in the water bright band were $\sim 0.03-0.06$, indicating that the enhanced lidar backscattering therein was caused mainly by high-concentration quasi-spherical raindrops with diameters $\leq 1$ $\mathrm{mm}$. The water bright band actually represents a major precipitation-related lidar backscattering layer in the liquid-phase stage of the light precipitation event. The water bright band appeared to have a larger vertical extent $(\sim 1.26-\mathrm{km})$ than that of the lidar ice bright band.

The lidar $q_{v}$ profile (Figure 3c) shows an enhanced water vapor mixing ratio at altitudes from $\sim 1.7-3.4 \mathrm{~km}$, indicating the subcloud evaporation of precipitating hydrometeors. In particular, $q_{v}$ was maximized $\left(5.95 \mathrm{~g} \mathrm{~kg}^{-1}\right)$ around the water bright band center (at $\sim 2.34 \mathrm{~km}$ ), suggesting that this altitude was a primary subcloud evaporation region for this light warm-front precipitation event. Furthermore, the $q_{v}$ values in the water bright band increased as precipitation continued (Figure 1c). Combining the vertical structures of $X, \delta_{v}$ and $q_{v}$ in the water bright band (Figs. 1 and 3) yields the suggestion that most falling pristine raindrops shrunk or vanished in the water bright band due to evaporation, whereas a small portion of them grew to large sizes via collision-coalescence processes and fell out of the water bright band.

At altitudes below the water bright band, the precipitation-related lidar backscattering $(X)$ apparently weakened (Figure 3a, in which the enhanced $X$ values at altitudes from $0.3-0.7 \mathrm{~km}$ resulted from the boundary layer aerosols), whereas $\delta_{v}$ first increased with decreasing height and then decreased after reaching a maximum $(0.13-0.16)$ at an altitude of approximately $0.6 \mathrm{~km}$ (Figure $3 \mathrm{~b}$ ). In fact, prominent $\delta_{v}$ peaks $(\sim 0.1-0.4)$ at altitudes of approximately $0.6 \mathrm{~km}$ are always observed in the $\delta_{v}$ profiles related to surface precipitation in the present light rain case (Figure 1). The $\delta_{v}$ maxima at an altitude of $\sim 0.6-\mathrm{km}$ are much larger than the typical values (less than $\sim 0.07$ ) observed by our 355 -nm polarization lidar at approximately the same altitude during rainless days. Therefore, our observational results suggest that sparse large raindrops that fall out of the water bright band with higher fall velocities further grow in size by collecting smaller raindrops along their fall paths. They grow

240 to sizes at which spontaneous breakup occurs at an altitude of approximately $0.6 \mathrm{~km}$. In their further descent, the large raindrops break up into small raindrops, yielding a decrease in the depolarization ratio at altitudes below $0.6 \mathrm{~km}$. As seen in Figure $1 \mathrm{~b}$, the boundary layer aerosols had little impact on the $\delta_{v}$ precipitation streaks. In addition, at altitudes below $1.5 \mathrm{~km}$, the $q_{v}$ values decreased with increasing altitude, reflecting a normal altitude distribution of the boundary layer water vapor.

245 Based on the radiosonde temperature data obtained at approximately 2000 LT on 27 December 2017 (Figure 2a, orange), the $0{ }^{\circ} \mathrm{C}$ isotherm level was at an altitude of $\sim 3.6 \mathrm{~km}$, and a warm-front-related inversion layer appeared just below the $0{ }^{\circ} \mathrm{C}$ level with a local temperature maximum $\left(2.2^{\circ} \mathrm{C}\right)$ at $3.33 \mathrm{~km}$ and a local minimum $\left(1.0^{\circ} \mathrm{C}\right)$ at $2.84 \mathrm{~km}$. The lidar dark band (at $2.88 \mathrm{~km}$, with a temperature of $\sim 1.0{ }^{\circ} \mathrm{C}$ ) was located $\sim 720 \mathrm{~m}$ below the $0{ }^{\circ} \mathrm{C}$ level. In comparison with the results 
reported in the literatures (Sassen and Chen, 1995; Demoz et al., 2000; Sassen et al., 2005; Di Girolamo et al., 2012), the observed $\sim 720$ - $\mathrm{m}$ distance of the dark-band minimum to the $0{ }^{\circ} \mathrm{C}$ level and the low dark-band temperature $\left(\sim 1.0{ }^{\circ} \mathrm{C}\right)$ are somewhat peculiar for light precipitation cases. In the current case, the melting process might be delayed by the temperature structure (with a small lapse rate) of the inversion layer.

Figure 4 presents three 1-min lidar $X$ and $\delta_{v}$ profiles displaying the timespan from 0230 to 0232 LT on 28 December 2017 and a one-hour-averaged lidar $q_{v}$ profile centered at $0231 \mathrm{LT}$ on the same day, depicting the microphysical process of precipitating hydrometeors for slightly strong surface rainfall during the light rain event. Although the water bright band and aerosol backscatter layer below the dark band became evidently weak compared to those seen in Figure $3 a$ (due to precipitation attenuation), the altitude of the dark-band minimum $(2.85 \mathrm{~km})$ was very close to that $(2.88 \mathrm{~km})$ obtained from Figure 3a. The magnitude $(\sim 0.03)$ and occurrence altitude $(2.76 \mathrm{~km})$ of the local $\delta_{v}$ minimum were consistent with the 260 corresponding values (less than 0.04 and $2.76 \mathrm{~km}$, respectively) observed in Figure 3b. Furthermore, the depolarization maxima associated with surface rainfall still appeared at an altitude of approximately $0.6 \mathrm{~km}$, which was also similar to that seen in Figure 3. The observational facts confirm the result gathered from our water splashing experiment in which the thin liquid water layer on the roof windows of the lidars caused only altitude-independent attenuation on the $X$ profiles and had nearly no effect on the $\delta_{v}$ profiles. The profile characteristics shown in Figure 4 are mostly similar to those mentioned above

265 for Figure 3, but some newly emerging features need to be illustrated. Figure 4 exhibits an ice bright band stronger than the concurrent water bright band. This result is different from our observations obtained at 0112 LT (Figure 3) but is consistent with earlier lidar observations (Sassen and Chen, 1995; Di Girolamo et al., 2012). The ice bright band observed at approximately $0230 \mathrm{LT}$ had the $X$ maxima at its bottom (at an altitude of $\sim 3.0 \mathrm{~km})$ and a small vertical extent $(\sim 0.21 \mathrm{~km}$, from 3.00 to $\sim 3.21 \mathrm{~km}$ due to precipitation attenuation). The $X$ maxima corresponded to the local minima of the

270 depolarization ratio (Figs. 4a and $4 \mathrm{~b}$ ). Interestingly, this inverse relationship between the backscatter and depolarization values on the bottom of the ice bright band is nearly ubiquitous in the precipitation lidar profiles obtained in the present case. Since the depolarization $\delta_{v}$ showed moderate minima $(\sim 0.08-0.10)$ at an altitude of $\sim 3.0 \mathrm{~km}$ (Figure $4 \mathrm{~b}$ ), the ice bright band maxima observed at approximately 0230 LT might reflect backscattering from high-concentration partially melted large particles therein. On the band's altitudinal extension (from 3.06-3.21 km), the markedly enhanced depolarization values 275 ( 0.17-0.34) indicate the presence of ice crystals and large snowflakes (Sassen and Chen, 1995; Di Girolamo et al., 2012). The water vapor mixing ratio $q_{v}$ showed slight enhancements at altitudes of $\sim 1.5-3.0 \mathrm{~km}$ at approximately $0230 \mathrm{LT}$ compared with that measured at approximately $0112 \mathrm{LT}$.

As seen from the $X$ and $\delta_{v}$ precipitation streaks at altitudes below $\sim 1.5 \mathrm{~km}$ (Figs.1a and 1b), surface rainfall was intermittent.

During periods without surface rainfall, our lidars were able to sample both complete virgae (from the rain to the snow regions) and their parent clouds under weak optical attenuation conditions. Such an example is shown in Figure 5. In this 
example, the parent cloud was a thin liquid-phase layer (with low $\delta_{v}$ values of $\sim 0.01$ ) at an altitude of $\sim 4.6 \mathrm{~km}$; the parent cloud had a temperature of $\sim-8.5{ }^{\circ} \mathrm{C}$ based on the radiosonde data. The $\delta_{v}$ value of the falling virga increased from $\sim 0.03-0.10$ (supercooled liquid-drop-dominated hydrometeors) at an altitude of $4.35 \mathrm{~km}$ to $\sim 0.21-0.33$ (ice/snow) at an altitude of $4.0 \mathrm{~km}$, suggesting that most supercooled liquid drops falling out of their liquid parent cloud rapidly froze into ice crystals. Note that there was no significant ice seeding from above the liquid parent cloud. Since warm-front-related largescale advection would bring aerosol particles to the freezing altitude range, a potential mechanism for ice crystal formation might be contact freezing. The falling ice crystals yielded a very weak ice bright band at an altitude of $\sim 3.0 \mathrm{~km}$, and then melted into liquid drops at an altitude of $\sim 2.76 \mathrm{~km}$ (the local $\delta_{v}$ minimum). During their further descent, the liquid drops fully vanished due to evaporation, leaving a lidar-detectable rain virga (water bright band) without surface precipitation. In contrast to the situation during surface rainfall, no clear-cut $\delta_{v}$ enhancement occurred at an altitude of approximately $0.6 \mathrm{~km}$ during the virga occurrence. Similar results were discerned for other lidar profiles shown in Figure 1, in which both a complete virga and its parent cloud could be detected. Interestingly, the features of both the virga's upper part and its parent cloud shown here resemble our previous observations on a sublimated ice virga and its supercooled liquid stratiform parent cloud (Cheng and Yi, 2020).

During the light warm-front rain event, since the surface rainfalls and virgae occurred alternately on a small time scale from a few minutes to tens of minutes and since their precipitation streaks had nearly the same dark-band structures (Figures 1a and $1 \mathrm{~b}$ ), both surface rainfall and virgae would come from the same parent cloud (because a warm-front cloud system is generally widespread and slowly varying). Surface rainfall (drizzle) arose when the precipitation rate was high below the parent cloud base, while virgae without surface rainfall took place when the subcloud precipitation rate was slightly low. Therefore, the current lidar observations reveal the microphysical process of precipitating hydrometeors related to light warm-front rain. Both rainfall at the surface and virgae suspended in air began as supercooled liquid-drop-dominated hydrometeors (with little ice or no ice) falling out of a liquid parent cloud layer at altitudes above $(\sim 1.0 \mathrm{~km})$ the $0{ }^{\circ} \mathrm{C}$ isotherm level. Most supercooled liquid drops quickly froze into ice particles during the first 100-200 $\mathrm{m}$ of their descent (via contact freezing). Their freezing time would be $25-50 \mathrm{~s}$ given a falling velocity of $4 \mathrm{~ms}^{-1}$ for $\sim 1.0$-mm liquid drops. Subsequently, the falling hydrometeors yielded a dense layer with an ice/snow bright band occurring above and a liquidwater bright band occurring below (separated by a lidar dark band) as a result of crossing the $0{ }^{\circ} \mathrm{C}$ level. In the ice/snow bright band, large particles would form via the cold rain processes (riming and aggregation) because the raindrop-to-snow transition would slowed down falling hydrometeors to yield local accumulation (note that the broad size distributions of the pristine hydrometeors falling out of the parent cloud base could also lead to local accretion). The production efficiencies of large particles would depend on the magnitude of the rain rate below the parent cloud base and size distributions of the pristine falling hydrometeors. The completion of the melting process of most falling ice particles appeared at altitudes (hundreds of meters) below the $0{ }^{\circ} \mathrm{C}$ isotherm level, as indicated by the local depolarization minimum observed immediately 
315 beneath ( $\sim 100 \mathrm{~m}$ below) the lidar dark-band minimum. After going through the dark band, most falling raindrops shrank or vanished in the water bright band due to evaporation, whereas a few large raindrops survived and fell out of the water bright band when the rain rate below the parent cloud base was high enough. The large raindrops might come from both the complete melting of large falling ice/snow particles and collision-coalescence formation in the dense water bright band. Sparse, large raindrops with high fall velocities further grew in size by collecting smaller raindrops along their fall paths. At an altitude of $\sim 0.6 \mathrm{~km}$, the large raindrops grew to the sizes at which spontaneous breakup could occur, yielding surface rainfall. When the rain rate below the parent cloud base was low, nearly none of the large raindrops fell out of the water bright band. Consequently, there were only virgae suspended on air (without surface rainfall). The lidar profiles for the virgae showed very small backscatter maxima on the ice bright band and narrower and weaker water bright bands than those observed during surface rainfall. Moreover, during virga occurrence, there was no perceptible depolarization enhancement at an altitude of $\sim 0.6 \mathrm{~km}$.

\subsection{Moderate warm-front precipitation (4 March 2019)}

Figure 6 shows an example of moderate warm-front precipitation that occurred on 4 March 2019. Both the descending precursor clouds and the $X$ and $\delta_{v}$ precipitation streaks are generally similar to those seen in the first example (Figure 1). The precursor clouds are cirrus (photo I in Figure 6), altostratus (photo II) and altocumulus (photo III). The surface rainfall started just after the subcloud ice virgae reached an altitude $(\sim 2.7 \mathrm{~km})$ slightly lower than the $0{ }^{\circ} \mathrm{C}$ level $(\sim 3.0 \mathrm{~km})$. The $\delta_{v}$ precipitation streaks show the upper portion (ice bright band) containing ice/snow particles (mostly $\delta_{v}>0.3$ ) and the lower portion (water bright band and below) being composed of liquid drops $\left(\delta_{v} \leq \sim 0.12\right.$ except for the $\delta_{v}$ maxima that occurred due to raindrop-size growth at an altitude of $\sim 0.6 \mathrm{~km}$ ). The $\delta_{v}$ values in both the ice bright band and water bright band (Figure 6b) were generally larger than their counterparts in the light rain example (Figure 1b), indicating that more large ice/snow particles and raindrops were involved in the moderate precipitation even than in the light precipitation event. Partially melted, large falling particles sometimes concealed the lidar dark band produced by the melting effect of most relatively small-sized particles in precipitating hydrometeors, making the band somewhat fuzzy (Figure 6a). Accordingly, the altitude of the local $\delta_{v}$ minimum (on the lidar dark band) became somewhat unsteady (Figure $6 \mathrm{~b}$ ). The $\delta_{v}$ maxima at an altitude of approximately $0.6 \mathrm{~km}$ (Figure $6 \mathrm{~b}$ ) were apparently larger than those shown in Figure $1 \mathrm{~b}$, indicating that more breakup-size raindrops formed via collision-coalescence processes therein than in the light rain case. Specifically, the $\delta_{v}$ maxima at an altitude of $\sim 0.6 \mathrm{~km}$ were as high as $\sim 0.27-0.35$ at $\sim 2338 \mathrm{LT}$, which corresponded well to the large surface rainfall rate of $3.2 \mathrm{~mm} \mathrm{~h}^{-1}$ measured from our rain gauge. The parent cloud for this moderate rain event was invisible by the lidars due to strong optical attenuation. A strong southerly wind prevailed at altitudes of $0-12 \mathrm{~km}$ in light of the radiosonde data obtained at 2000 LT on 4 March 2019. A high-concentration moisture layer appeared in the subcloud region at altitudes from $\sim 0.5$ to $\sim 3.0 \mathrm{~km}$ during the rainfall event, indicating the subcloud evaporation of precipitating hydrometeors. The moderate rainfall lasted for $\sim 14 \mathrm{~h}$, yielding an accumulated surface rainfall amount of $23.9 \mathrm{~mm}$. 


\subsubsection{Associated meteorological conditions}

The conventional radiosonde profiles associated with the moderate warm-front precipitation and its precursor clouds and the 1-h mean lidar profiles obtained during the radiosonde launches are plotted in Figure 7. At $~ 0800$ LT on 4 March 2019, the sky was nearly cloudless (Figure 7d, blue), and high relative humidity occurred only at altitudes below $1.2 \mathrm{~km}$ (Figure 7b, blue), while the northwesterly wind prevailed at altitudes from $1.7-10.5 \mathrm{~km}$. This indicated that the warm front had not yet reached our lidar site. At $\sim 2000$ LT on 4 March, a moist layer occurred at altitudes ranging from $\sim 4.8$ to $8.0 \mathrm{~km}$ with increased relative humidity over water of $80-95 \%$ (Figure $7 \mathrm{~b}$, green). An evaporating ice virga was observed at altitudes from $~ 3.6-4.6 \mathrm{~km}$ (Figures $7 \mathrm{~d}$ and 7e, green), just below the moisture layer peak. The parent cloud of the virga was invisible by lidars due to strong optical attenuation. A potential occurrence region for the parent cloud ranged in altitude from 4.8-6.0 $\mathrm{km}$, where the relative humidity was larger than $90 \%$ (Figure $7 \mathrm{~b}$, green). The southerly wind prevailed at altitude from 0-12 $\mathrm{km}$ (Figure 7f, green), indicating that the moisture layer and altocumulus (photo III in Figure 6) were precursors of the warm-front precipitation event. The radiosonde profiles obtained at 0800 LT on 5 March 2019 showed the meteorological conditions during the moderate warm-front precipitation event after the lidar measurements had already terminated (at 0051

360 LT on 5 March). As shown in Figure $7 \mathrm{~b}$ (orange), the relative humidity over water had values of 97-98\% at altitudes from 0-5.65 $\mathrm{km}$, corresponding to a precipitation rate of $\sim 1.8 \mathrm{~mm} \mathrm{~h}^{-1}$ (rain gauge record) at approximately 0800 LT on 5 March. An alternate vertical structure in the northward wind component at altitudes from 0-6.6 km (Figure 7f, solid orange) suggested that a stationary front existed.

\subsubsection{Microphysical process of precipitating hydrometeors for the moderate warm-front rain}

365 Figure 8 presents three 1-min lidar $X$ and $\delta_{v}$ profiles measured from 2220 to 2222 LT on 4 March and a one-hour-averaged lidar $q_{v}$ profile centered at $2221 \mathrm{LT}$ on the same day; these profiles exhibit the vertical structure of the $X$ and $\delta_{v}$ precipitation streaks as well as the water vapor mixing ratio at the onset of the moderate warm-front precipitation event. The lidar profiles obtained at 2220 and 2221 LT show nearly identical dark-band locations (the $X$ minima is located at $2.04 \mathrm{~km}$, and the local $\delta_{v}$ minima is located at $\sim 1.96 \mathrm{~km}$ ). The dark-band minima appeared $\sim 960 \mathrm{~m}$ below the $0{ }^{\circ} \mathrm{C}$ level at a temperature of $\sim 6.0^{\circ} \mathrm{C}$. At $2222 \mathrm{LT}$, a weak $X$ peak occurred at the dark-band altitudes with $\delta_{v}$ values ranging from $\sim 0.21-0.29$, indicating that partially melted large particles passed through the dark band. As seen from Figure 8 , the $X$ and $\delta_{v}$ precipitation streaks had complicated vertical structures at altitudes below the dark band and showed strong variations on the time scale of minutes. In particular, enhanced depolarization (0.07-0.12) occurred within the water bright band. These profile details confirm that large-sized particles sometimes fell out of the ice bright band during the moderate warm-front precipitation event, concealing the lidar dark band produced by the melting effect of most relatively small-sized particles in precipitating hydrometeors. This effect appears to explain why the lidar dark band became fuzzy for the moderate precipitation event (Figure 6). Note that the $\delta_{v}$ maxima ( 0.2), which occurred at an altitude of approximately $0.6 \mathrm{~km}$, were slightly larger in the moderate warm-front 
rainfall than those observed in the light warm-front rainfall example. This suggests a larger concentration of raindrops of spontaneous breakup sizes around this altitude. The water vapor mixing ratio $q_{v}$ had values ranging from $3.4-4.4 \mathrm{~g} \mathrm{~kg}^{-1}$ at altitudes from $1.0-3.0 \mathrm{~km}$ (from the bottom of the water bright band to the $0^{\circ} \mathrm{C}$ level).

Figure 9 gives three 1-min lidar $X$ and $\delta_{v}$ profiles representing the period from 2337 to 2339 LT on 4 March 2019 and a onehour-averaged lidar $q_{v}$ profile centered at $2338 \mathrm{LT}$ on the same day; these profiles exhibit the vertical structures of the $X$ and $\delta_{v}$ precipitation streaks as well as the water vapor mixing ratio observed when the surface precipitation rate was highest (3.2 $\mathrm{mm} \mathrm{h}^{-1}$ ) during the moderate warm-front precipitation event (yielding thick liquid water accumulation on the roof windows of the lidars; see photo V in Figure 6). The ice bright band, dark band and water bright band were roughly discernible in the three 1-min $X$ profiles despite the considerable fluctuations that occurred on the time scale of minutes. Large ice/snow particles occurred on the ice bright band (at an altitude of approximately $2.5 \mathrm{~km}$ ) because the $\delta_{v}$ values were larger than 0.3 therein. The dark band located $\sim 700 \mathrm{~m}$ below the $0{ }^{\circ} \mathrm{C}$ level $(3.0 \mathrm{~km})$ had $\delta_{v}$ values ranging from $0.13-0.19$ and a temperature of $4.3{ }^{\circ} \mathrm{C}$, reflecting that there were partially melted large particles present in the dark band. In the height range of the water bright band, the depolarization ratio increased from $\sim 0.04-0.06$ at an altitude of approximately $2.09 \mathrm{~km}$ to $\sim 0.12-0.15$ at an altitude of $0.9 \mathrm{~km}$, indicating that more large raindrops formed via collision-coalescence processes therein than in the light warm-front rainfall example (Figures 3 and 4). The $\delta_{v}$ maxima observed at an altitude of $\sim 0.6 \mathrm{~km}$ were as high as $\sim 0.27-0.35$ corresponding well to the high measured surface rainfall rate of $3.2 \mathrm{~mm} \mathrm{~h}^{-1}$ (rain gauge record). The $q_{v}$ values at altitudes from $\sim 0.7-3.0 \mathrm{~km}$ ranged from 5.3-7.3 $\mathrm{g} \mathrm{kg}^{-1}$ (Figure 9c), indicating overall moisture enhancement compared to those values measured at the onset of the moderate warm-front precipitation event (Figure 8c).

\section{Summary and conclusions}

Observations of precipitation and associated precursor clouds were made with two collocated lidars (a 355-nm polarization lidar and water vapor Raman lidar) equipped with waterproof transparent roof windows at the Wuhan University atmospheric observatory $\left(30.5^{\circ} \mathrm{N}, 114.4^{\circ} \mathrm{E}, 80 \mathrm{~m}\right.$ above sea level). The lidar observations obtained during surface rainfall events indicate that the rainfall-induced liquid water accumulation on the roof windows of the lidars only yielded a heightindependent lidar signal (range-corrected signal $X$ ) attenuation, whereas neither the $X$ vertical structure nor the magnitude or vertical structure of the volume depolarization ratio $\left(\delta_{v}\right)$ were altered. Furthermore, the liquid water accumulation on the roof windows of the lidars also had nearly no effect on the obtained subcloud profiles of the water vapor mixing ratio measured by the Raman lidar. These observations are consistent with the results of our artificial water splashing experiment on the roof windows. 
Warm-front precipitation events and their precursor cloud evolutions were reported in this paper based on two case studies corresponding to light and moderate rainfall occurring at the Earth's surface. The lidar-observed precursor clouds showed a systematic descent for each case. The descending clouds changed gradually from cirrus and altocumulus to altostratus before rainfall occurred, with gradually increasing moisture, and the southwesterly wind prevailed over most altitude ranges of the cloud layers. These features indicate that, in each case, a warm front was approaching our lidar site. The precursor clouds had underlying ice virgae in their later descent phases. When the subcloud virgae reached an altitude slightly below the $0{ }^{\circ} \mathrm{C}$ level, rainfall at the surface began. The hours-long precipitation streaks shown in the lidar signal $(X)$ and volume

415 depolarization ratio $\left(\delta_{\mathrm{v}}\right)$ profiles reveal some ubiquitous features of the microphysical processes of precipitating hydrometeors.

For the light warm-front rain event, since the surface rainfall and virgae occurred alternately over a short time scale from a few minutes to tens of minutes and since their respective precipitation streaks had nearly the same dark-band structures, both surface rainfall and virgae originate from the same parent cloud (because a warm-front cloud system is generally widespread and slowly varying). Through an analysis combining the lidar profiles of surface rainfall and virgae, we find that the rainfall at the surface began as supercooled liquid-drop-dominated hydrometeors (with little ice or no ice) falling out of a liquid parent cloud at altitudes above $(\sim 1.0 \mathrm{~km})$ the $0{ }^{\circ} \mathrm{C}$ isotherm level. Most liquid drops quickly froze into ice particles during the first 100-200 m of their descent. Subsequently, the falling hydrometeors yielded a dense layer with an ice/snow bright band occurring above and a liquid-water bright band occurring below (separated by a lidar dark band) as a result of crossing the $0{ }^{\circ} \mathrm{C}$ level. In the ice/snow bright band, larger particles formed by riming and/or aggregation because the raindrop-tosnow transition slowed the falling hydrometeors to yield local accumulation (the broad size distributions of the pristine hydrometeors falling out of their parent cloud base could also lead to local accretion). The completion of the melting process of most falling ice particles appeared at altitudes (hundreds of meters) below the $0{ }^{\circ} \mathrm{C}$ isotherm level, as indicated by the local depolarization minimum located immediately beneath $(\sim 100 \mathrm{~m})$ the observed lidar dark-band minimum. After going through the dark band, most falling raindrops shrunk or vanished in the water bright band due to evaporation, whereas a few large raindrops survived and fell out of the water bright band when the rainfall rate below the liquid parent cloud base was high enough. Large raindrops might originate from both the complete melting of falling large ice/snow particles and collision-coalescence formation in the dense water bright band. We also find that a prominent depolarization $\delta_{\mathrm{v}}$ peak (0.10-0.35) always occurred at an altitude of approximately $0.6 \mathrm{~km}$ during surface rainfall, reflecting the collisioncoalescence growth of large falling raindrops (sparse large raindrops with high fall velocities further grew in size by collecting smaller raindrops along their fall paths) and subsequent spontaneous breakup. The $\delta_{\mathrm{v}}$ peak observed at an altitude of $\sim 0.6 \mathrm{~km}$ provides an indicator $\sim 1$-min in advance of surface rainfall. 
440 For the moderate warm-front rain event, although the parent cloud was unable to detect owing to strong attenuation, the lidar-detectable microphysical process (at the altitudes of the ice-bright-band and below) was similar to that observed in the light rain case. However, the $\delta_{v}$ values in both the ice bright band and water bright band were generally larger than their counterparts in the light rainfall case, indicating that more large ice/snow particles and raindrops were involved in moderate precipitation. Furthermore, the $X$ and $\delta_{v}$ precipitation streaks had complicated vertical structures at altitudes around and below the dark band and showed strong variations on the time scale of minutes. These profile details suggest that large particles sometimes fell out of the ice bright band during moderate precipitation, concealing the lidar dark band produced by the melting effect of most relatively small particles in precipitating hydrometeors. Thus, the lidar dark band became fuzzy. The $\delta_{v}$ maxima observed at an altitude of approximately $0.6 \mathrm{~km}$ were also larger than those observed in the light warm-front rain case. This suggests larger concentrations of raindrops with spontaneous breakup sizes around this altitude.

\section{Author contributions}

YY performed the lidar measurements, made the data analysis and wrote the initial manuscript. FY conceived the project, led the study and finalized the manuscript. FL, YZ and CY built the lidar systems for precipitation observations. YH participated in scientific discussions and suggested analysis. All authors discussed the results and commented on the manuscript.

\section{Competing interests}

The authors declare that they have no conflict of interest.

\section{Data availability}

Lidar data used in this work are available under permission (yf@whu.edu.cn).

\section{Acknowledgments}

This research is funded by the National Natural Science Foundation of China through grants 41927804 . The Meridian Space Weather Monitoring Project (China) also provides financial support for the lidar maintenance. The authors thank the University of Wyoming for providing the Wuhan radiosonde data at the website 465 (http://weather.uwyo.edu/upperair/sounding.html). Data used to generate the results of this paper are available from the authors upon request (E-mail: yf@whu.edu.cn). 


\section{References}

Aggarwal, P.K., Romatschke,U., Araguas-Araguas, L., Belachew, D., Longsta, F. J., Berg, P., Courtney Schumacher, C. and Funk, A.:Proportions of convective and stratiform precipitation revealed in water isotope ratios, Nature Geosci., 9, 624629,https://doi: 10.1038/NGEO2739, 2016.

Ansmann, A., M. Tesche, D. Althausen, D. Müller, P. Seifert, V. Freudenthaler, B. Heese, M. Wiegner, G. Pisani, P. Knippertz, and O. Dubovik: Influence of Saharan dust on cloud glaciation in southern Morocco during the Saharan Mineral Dust Experiment, J. Geophys. Res., 113(D4), D04210, https://doi:10.1029/2007JD008785, 2008.

Ansmann, A., M. Tesche, P. Seifert, D. Althausen, R. Engelmann, J. Fruntke, U. Wandinger, I. Mattis, and D. Müller: Evolution of the ice phase in tropical altocumulus: SAMUM lidar observations over Cape Verde, J. Geophys. Res., 114, D17208, https://doi:10.1029/2008JD011659, 2009.

Barrett, A. I., Westbrook, C. D., Nicol, J. C., and Stein, T. H. M.: Rapid ice aggregation process revealed through triplewavelength Doppler spectrum radar analysis, Atmos. Chem. Phys., 19(8), 5753-5769, https://doi: 10.5194/acp-19-5753-2019, 2019.

Bühl, J., Seifert, P., Myagkov, A., and Ansmann, A.: Measuring ice- and liquid-water properties in mixed-phase cloud layers at the Leipzig Cloudnet station, Atmos. Chem. Phys., 16(16), 10609-10620. https://doi: 10.5194/acp-16-10609-2016, 2016.

Bühl, J., Seifert, P., Radenz, M., Baars, H., and Ansmann, A.: Ice crystal number concentration from measurements of lidar, cloud radar and radar wind profiler. Atmos. Meas. Tech., 2019, 1-25, https://doi: 10.5194/amt-2019-154, 2019.

Cheng, C. and Yi, F.: Falling mixed-phase ice virga and their liquid parent cloud layers as observed by ground-based lidars, Remote Sens. 2020, 12, 2094, https://doi.org/10.3390/rs12132094, 2020.

de Boer, G., H. Morrison, M. D. Shupe, and R. Hildner: Evidence of liquid dependent ice nucleation in high-latitude stratiform clouds from surface remote sensors, Geophys. Res. Lett., 38, L01803, https://doi:10.1029/2010GL046016, 2011.

Demoz, B., D. Starr, D. Whiteman, K. Evans, D. Hlavka, and R. Peravali: Raman lidar detection of cloud base, Geophys. Res. Lett., 27, 1899-1902, https://doi:10.1029/1999GL010941,2000. 
500 Di Girolamo, P., Summa, D., Cacciani, M., Norton, E. G., Peters,G., and Dufournet, Y.: Lidar and radar measurements of the melting layer: observations of dark and bright band phenomena, Atmos. Chem. Phys., 12, 4143-4157, https://doi:10.5194/acp-12-4143-2012, 2012.

Field, P. and Heymsfield, A.: Importance of snow to global precipitation, Geophys. Res. Lett., 42, 9512-9520, https://doi:10.1002/2015GL065497, 2015.

Freudenthaler, V., Esselborn, M., Wiegner, M., Heese, B., Tesche, M., Ansmann, A., Müller, D., Althausen, D., Wirth, M., Fix, A., Ëhret, G., Knippertz, P., Toledano, C., Gasteiger, J., Garhammer, M., and Seefeldner, M.: Depolarization ratio profiling at several wavelengths in 5 pure Saharan dust during SAMUM 2006, Tellus B, 61, 165-179, 510 https://doi:10.1111/j.1600-0889.2008.00396.x, 2009.

Intrieri, J. M., Shupe, M. D., Uttal, T., and McCarty, B. J.: An annual cycle of Arctic cloud characteristics observed by radar and lidar at SHEBA, J. Geophys. Res., 107(C10), https://doi:10.1029/2000JC000423, 2002.

515 Kong, W., and F. Yi: Convective boundary layer evolution from lidar backscatter and its relationship with surface aerosol concentration at a location of a central China megacity, J. Geophys. Res. Atmos., 120, 7928-7940, https://doi:10.1002/2015JD023248, 2015.

Mega, T., M. K. Yamamoto, M. Abo, Y. Shibata, H. Hashiguchi, N. Nishi, T. Shimomai, Y. Shibagaki, M. Yamamoto, M. D.

520 Yamanaka, S. Fukao and T. Manik: First simultaneous measurement of vertical air velocity, particle fall velocity, and hydrometeor sphericity in stratiform precipitation: Results from 47-MHz wind profiling radar and 532-nm polarization lidar observations, Radio Sci., 47, RS3002, https://doi:10.1029/2011RS004823, 2012.

Mülmenstädt, J., Sourdeval, O., Delanoe, J., and Quaas, J.: Frequency of occurrence of rain from liquid-, mixed-, and icephase clouds derived from A-Train satellite retrievals, Geophys. Res. Lett., 42(15), 6502-6509, https://doi:10.1002/2015gl064604, 2015.

Nash, J., T. Oakley, H. Vömel, and W. Li: WMO Intercomparison of High Quality Radiosonde Systems, Yangjiang, China, vol. 107, p. 238, World Meteorological Organization, Instruments and Observing methods, Geneva, Switzerland, 2011.

Newsom, R. K., D. D. Turner, B. Mielke, M. Clayton, R. Ferrare, and C. Sivaraman: Simultaneous analog and photon counting detection for Raman lidar, Appl. Opt., 48, 3903-3914, https://doi:10.1364/AO.48.003903, 2009. 
Pfitzenmaier, L., Unal, C. M. H., Dufournet, Y. and H. W. J. Russchenberg: Observing ice particle growth along fall streaks 18-7843-2018, 2018.

Roy, G., and L. R. Bissonnette: Strong dependence of rain-induced lidar depolarization on the illumination angle: Experimental evidence and geometrical-optics interpretation, Appl. Opt., 40, 4770-4780,https://doi:10.1364/AO.40.004770, 2001.

Sassen, K. and Chen, T.: The lidar dark band: An oddity of the radar bright band, Geophys. Res. Lett., 22, 3505-3508, https://doi:10.1029/95GL03367, 1995.

545 Sassen, K., Campbell, J. R., Zhu, J., Kollias, P., Shupe, M., and Williams, C.: Lidar and triple-wavelength Doppler radar measurements of the melting layer: A revised model for dark and bright band phenomena, J. Appl. Meteor., 44, 301-312, https://doi:10.1175/JAM-2197.1, 2005.

Shupe, M.D.: A ground-based multisensor cloud phase classifier, Geophys. Res. Lett., VOL. 34, L22809, https://doi:10.1029/2007GL031008, 2007.

Shupe, M. D., J. S. Daniel, G. de Boer, E. W. Eloranta, P. Kollias, C. N. Long, E. P. Luke, D. D. Turner, and J. Verlinde: A focus on mixed-phase clouds, Bull. Am. Meteorol. Soc., 89, 1549 - 1562, https://doi:10.1175/2008BAMS2378.1, 2008.

Whiteman, D. N., S. H. Melfi, and R. A. Ferrare: Raman lidar system for the measurement of water vapor and aerosols in the Earth's atmosphere, Appl. Opt., 31(16), 3068-3082, https://doi:10.1364/AO.31.003068,1992.

$\mathrm{Wu}, \mathrm{C}$, and F. Yi: Local ice formation via liquid water growth in slowly ascending humid aerosol/liquid water layers observed with ground-based lidars and radiosondes, J. Geophys. Res. Atmos., 122, 4479-4493, https://doi:10.1002/2016JD025765, 2017.

Zhang, Y., F. Yi, W. Kong, and Y. Yi.: Slope characterization in combining analog and photon count data from atmospheric lidar measurements, Appl. Opt., 53, 7312-7320, https://doi:10.1364/AO.53.007312, 2014. 


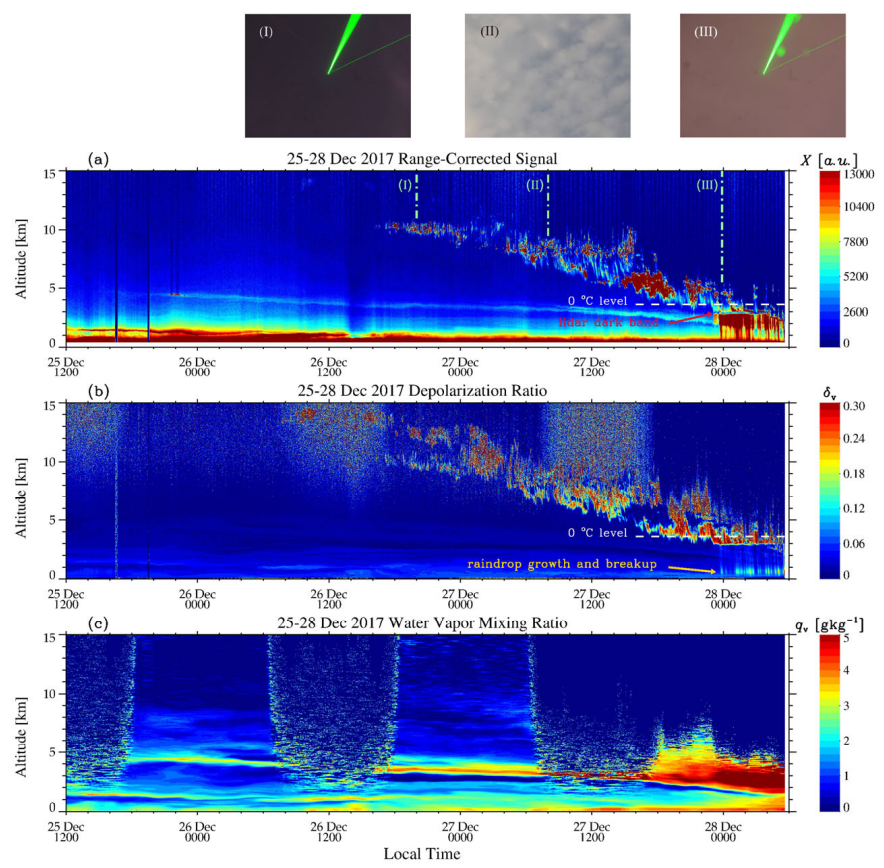

Figure 1: Time-height contour plots $\left(1 \mathrm{~min} / 30 \mathrm{~m}\right.$ resolution) of the (a) range-corrected signal $X$, (b) volume depolarization ratio $\delta_{v}$ measured by a 355-nm polarization lidar, and (c) water vapor mixing ratio $q_{v}$ measured by a water vapor Raman lidar on 25-28 December 2017, which exhibited the passage of a warm front and the resulting hours-long light rain. A sliding average of $60 \mathrm{~min}$ 570 was applied to the Raman lidar data. A descending precursor cloud layer was present at altitudes of $\sim 3.0-10.0 \mathrm{~km}$ between 1600 LT on 26 December and 2351 LT on 27 December 2017. After the subcloud ice virgae reached an altitude $(\sim 3.0 \mathrm{~km})$ that was lower than the $0{ }^{\circ} \mathrm{C}$ isotherm level $\left(\sim 3.6 \mathrm{~km}\right.$, radiosonde data), surface rainfall arose (precipitation streaks shown in the $X$ and $\delta_{v}$ contour plots). The light rain lasted for $\sim 8 \mathrm{~h}$ and yielded an accumulated surface rainfall amount of $2.6 \mathrm{~mm}$. A lidar dark band definitely differentiated between two altitudinal regions: one region with precipitating ice-containing hydrometeors above the dark band and another region with liquid raindrops below the dark band. Prominent $\delta_{v}$ peaks $(\sim 0.1-0.4)$ at altitudes of approximately $0.6 \mathrm{~km}$ could always be observed from the $\delta_{v}$ profiles related to surface precipitation. During rainfall, the $q_{v}$ values increased significantly in the upper portions of the precipitation streaks. Shown on the top of the figure are the corresponding photographs of the sky taken by a ground-based camera at our lidar site, with the third photograph exhibiting the sky illuminated by a 532-nm laser beam during the onset of rainfall. 
(a)

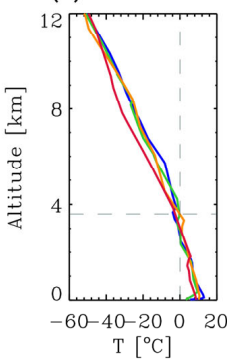

(b)

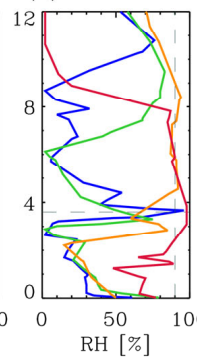

(c)

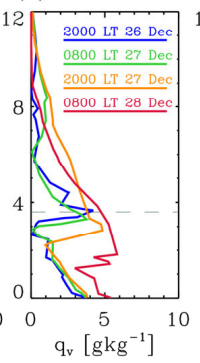

(d)

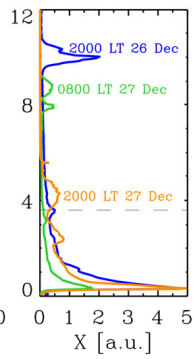

(e)

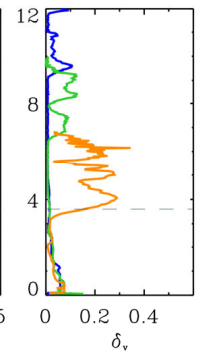

(f)

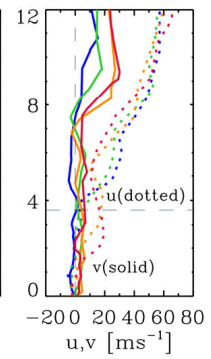

Figure 2: Sequential profiles of (a) temperature $T$, (b) relative humidity over liquid water $R H$, (c) water vapor mixing ratio $q_{v}$ and (f) the eastward $u$ (dotted) and northward $v$ (solid) wind components delivered by conventional radiosonde measurements (twice daily) released on 26-28 December 2017 at the Wuhan weather station $(\sim 23.4 \mathrm{~km}$ away from our lidar site). Also shown are the 585 corresponding profiles of the (d) range-corrected signal $X$ and (e) volume depolarization ratio $\delta$, measured by the 355-nm polarization lidar on 26-27 December 2017. The different curve colors in each panel represent the radiosonde release times, as shown in Figure 2c. Each colored lidar profile represents a 1-h integration centered at the radiosonde release time marked in Figure 2d. The radiosonde profiles quantitatively present the meteorological conditions that are pertinent to the warm front cloud at different stages and during precipitation.

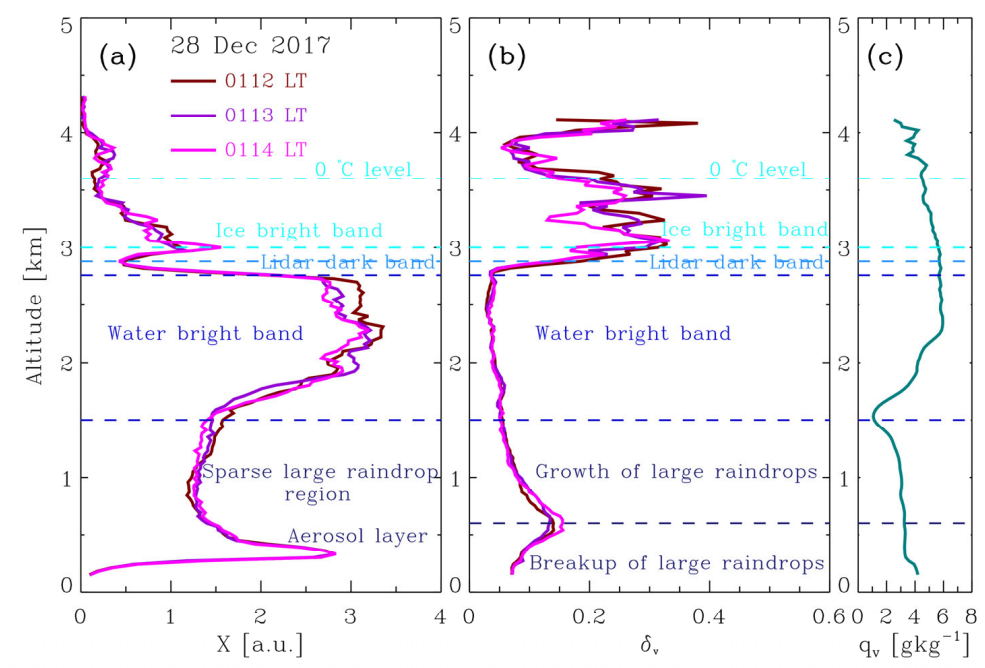

Figure 3: Lidar profiles for weak surface rainfall (drizzle). (a), Range-corrected 355-nm signal $X$ profiles from 0112 to 0114 LT on 28 December 2017; (b), 355-nm volume depolarization ratio $\delta_{v}$ profiles in the same period; and (c), one-hour-averaged lidar $q_{v}$ profile centered at $0113 \mathrm{LT}$ on the same day. An ice-containing bright band with $\delta_{\mathrm{v}}$ values varying from $\sim 0.13$ to $\sim 0.39$ was 

$1.50-2.76 \mathrm{~km}$ with $\delta_{\mathrm{v}}$ values ranging from $\sim 0.05($ at $1.50 \mathrm{~km})$ to $\sim 0.03($ at $2.76 \mathrm{~km})$. The $\delta_{\mathrm{v}}$ profiles revealed maximum values $(\sim 0.16)$ at nearly the same altitude $(\sim 0.6 \mathrm{~km})$. In the altitude range from $0.6-1.29 \mathrm{~km}$, large raindrops with high fall speeds grew further 600 by collecting relatively slowly falling, small drops on their paths. The spontaneous breakup of precipitating large raindrops took place at altitudes below $0.6 \mathrm{~km}$. The water vapor mixing ratio $q_{\mathrm{v}}$ showed enhancement at altitudes from $2.16-3.21 \mathrm{~km}$, representing the subcloud evaporation of precipitating hydrometeors.
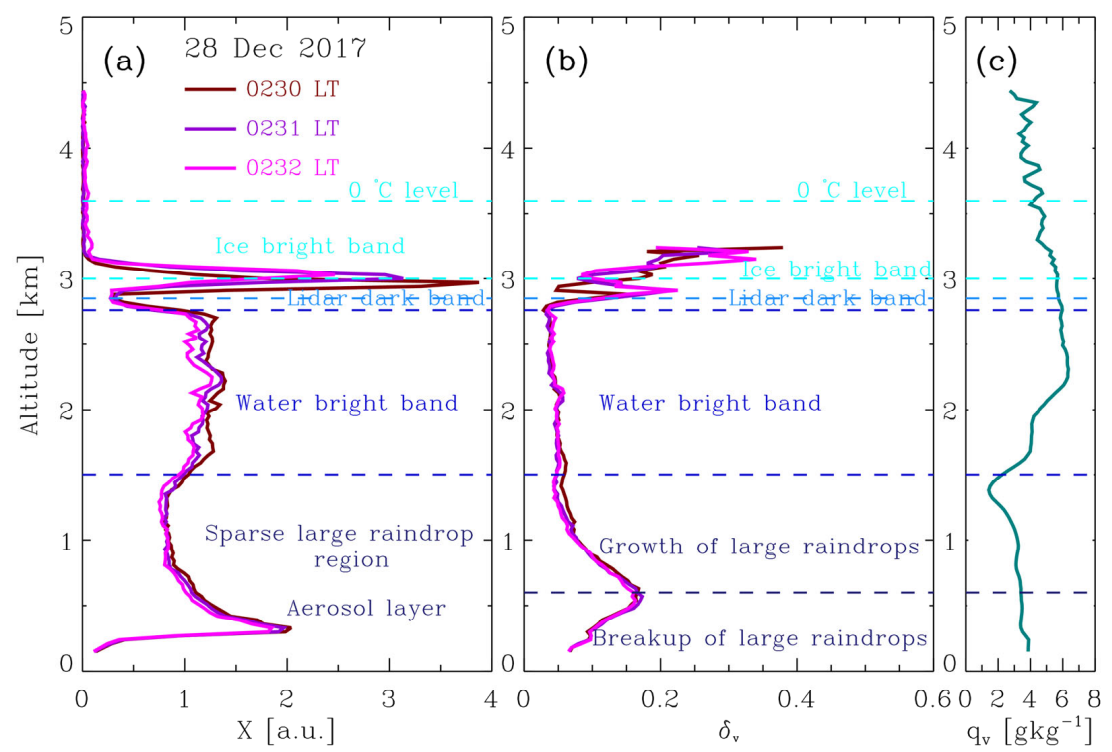

Figure 4: Lidar profiles for slightly strong surface rainfall period (in light rain). (a), Range-corrected 355-nm signal $X$ profiles covering the period from 0230 to $0232 \mathrm{LT}$ on 28 December 2017; (b), 355-nm volume depolarization ratio $\delta_{v}$ profiles covering the same period; (c), one-hour-averaged lidar $q_{v}$ profile centered at 0231 LT on the same day. A lidar dark band ( $X$ minimum at an

610 altitude of $\sim 2.85 \mathbf{~ k m}$ ) differentiates the altitude regions of precipitating ice-containing hydrometeors occurring above and liquid raindrops occurring below. The $\delta_{v}$ profiles still revealed maximum values $(\sim 0.17)$ at nearly the same altitude $(\sim 0.6 \mathrm{~km})$. In the altitude range from $0.6-1.50 \mathrm{~km}$, large raindrops with higher fall velocities grew further by collecting relatively slowly falling, small drops along their paths. The spontaneous breakup of precipitating large raindrops took place at altitudes below $0.6 \mathrm{~km}$. The water vapor mixing ratio $q_{v}$ showed enhancement at altitudes from 2.16-3.21 km, representing the subcloud evaporation of 615 precipitating hydrometeors. 


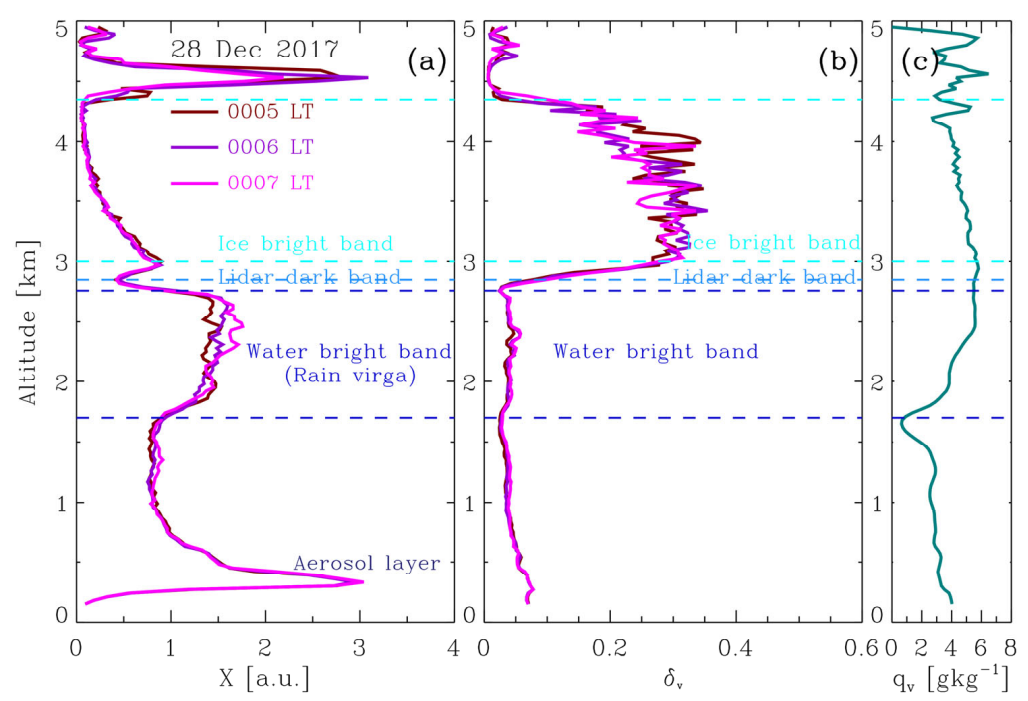

620 Figure 5: Lidar profiles for a virga and its parent cloud occurring between intermittent surface rainfalls. (a), Range-corrected 355nm signal $X$ profiles from 0005 to 0007 LT on 28 December 2017; (b), 355-nm volume depolarization ratio $\delta_{v}$ profiles in the same period; and (c), one-hour-averaged lidar $q_{\mathrm{v}}$ profile centered at $0006 \mathrm{LT}$ on the same day. The parent cloud is a thin supercooled liquid-phase layer (with low $\delta_{v}$ values of $\sim 0.01$ ) at an altitude of approximately $4.6 \mathrm{~km}$ (at a temperature of $\sim-8.3{ }^{\circ} \mathrm{C}$ ). The depolarization ratio $\delta_{v}$ of the falling virga below the parent cloud increased from $\sim 0.03-0.10$ at an altitude of $4.35 \mathrm{~km}$ to $\sim 0.21-0.33$ at $4.0 \mathrm{~km}$, suggesting that most supercooled liquid drops falling out of their liquid parent cloud were rapidly froze into ice crystals. These falling ice crystals yielded a very weak ice bright band at an altitude of $\sim 3.0 \mathrm{~km}$ and then melted into liquid drops at an altitude of $2.76 \mathrm{~km}$ (the local $\delta_{\mathrm{v}}$ minimum). During their further descent, the drops evaporated completely at an altitude of approximately $1.7 \mathrm{~km}$ altitude, giving rise to no surface precipitation. Note that the lidar did not detect $\delta_{v}$ enhancement at an altitude of $\sim 0.6 \mathrm{~km}$ in the virga period, in contrast to the situation observed during surface rainfall. 

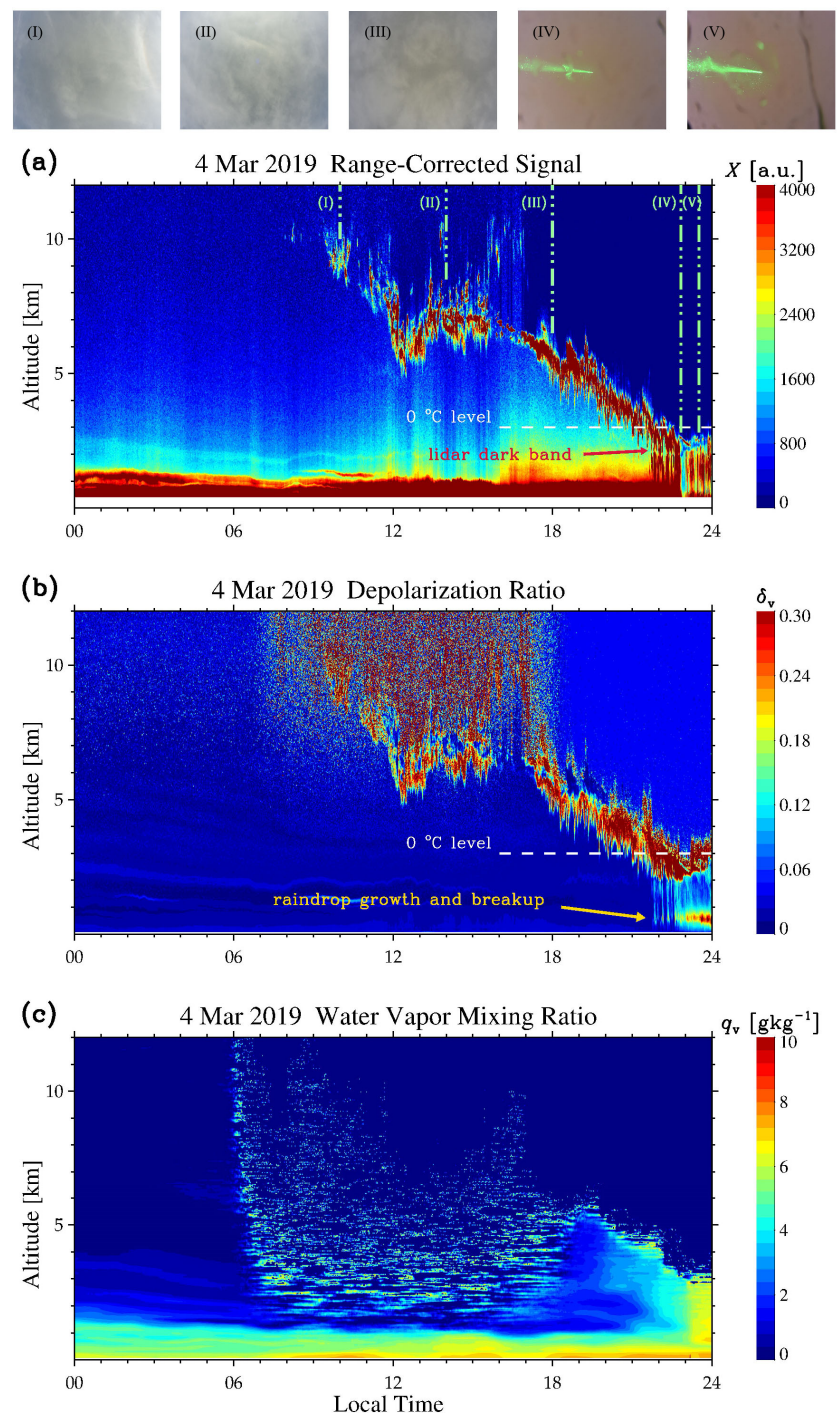

Figure 6: Lidar observations (contour plots with $1 \mathrm{~min} / 30 \mathrm{~m}$ resolution) of a moderate warm-front precipitation event. (a), Rangecorrected 355-nm signal $X ;(b), 355-\mathrm{nm}$ volume depolarization ratio $\delta_{\mathrm{v}}$; and (c), water vapor mixing ratio $q_{\mathrm{v}}$ (a sliding average of 60 min was applied). A descending precursor cloud layer was present at altitudes of $\sim 2.7-7.0 \mathrm{~km}$ between $\sim 1330 \mathrm{LT}$ and $2148 \mathrm{LT}$ on 4 March 2019. After the subcloud ice virgae reached at an altitude $(\sim 2.7 \mathrm{~km})$ slightly lower than the $0{ }^{\circ} \mathrm{C}$ temperature level $(\sim 3.0 \mathrm{~km})$, surface-reaching precipitation (precipitation streaks shown in the $X$ and $\delta_{\mathrm{v}}$ contour plots) occurred. The moderate rainfall lasted for $\sim 14 \mathrm{~h}$, yielding an accumulated surface rainfall amount of $23.9 \mathrm{~mm}$. Shown on the top of the figure are 

the rainy sky illuminated by a 532-nm laser beam.

(a)

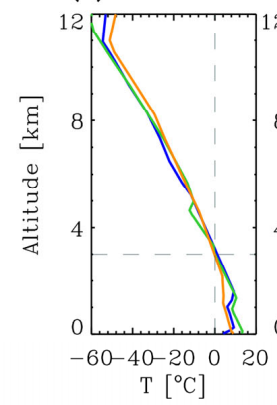

(b)

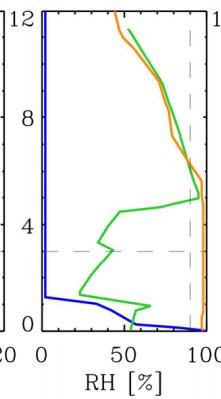

(c)

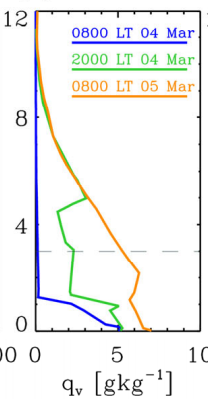

(d)

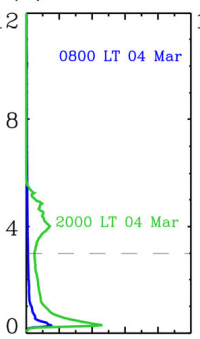

$\begin{array}{llllll}0 & 0 & 1 & 2 & 3 & 4\end{array}$ (e)

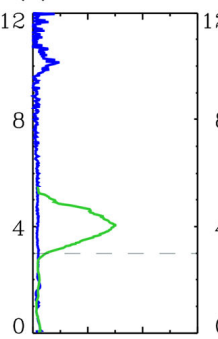

20.4 (f)

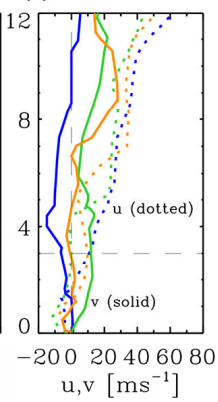

Figure 7: Sequential profiles of (a) temperature $T$, (b) relative humidity over liquid water $R H$, (c) water vapor mixing ratio $q_{v}$ and (f) the eastward $u$ (dashed) and northward $v$ (solid) wind components delivered by conventional radiosondes (twice daily) released on 4-5 March 2019 at the Wuhan weather station. The corresponding profiles of the (d) range-corrected signal $X$ and (e) volume depolarization ratio $\delta$ measured by the 355-nm polarization lidar on 4 March 2017 are also shown. The different curve colors in 650 each panel represent the radiosonde release times, as shown in Figure 2c. Each colored lidar profile represents a 1-h integration centered at the radiosonde release time shown in Figure $2 \mathrm{~d}$. The radiosonde profiles quantitatively present the meteorological conditions pertinent to the warm-front clouds and precipitation. 


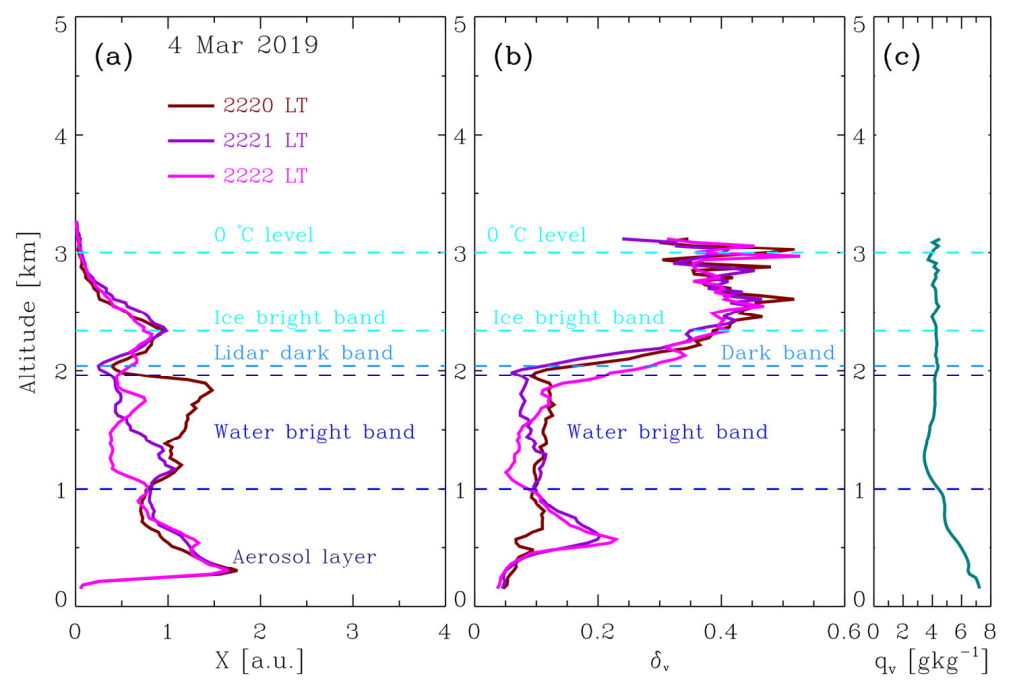

Figure 8: Three 1-min lidar $X$ and $\delta$ vrofiles obtained from 2220 to 2222 LT on 4 March 2019 and a one-houraveraged lidar $q_{\mathrm{v}}$ profile centered at $2221 \mathrm{LT}$ on the same day; the profiles, exhibit the vertical structure of the $X$ and $\delta_{\mathrm{v}}$ precipitation streaks as well as the water vapor mixing ratio at the onset of the moderate warm-front precipitation event. 


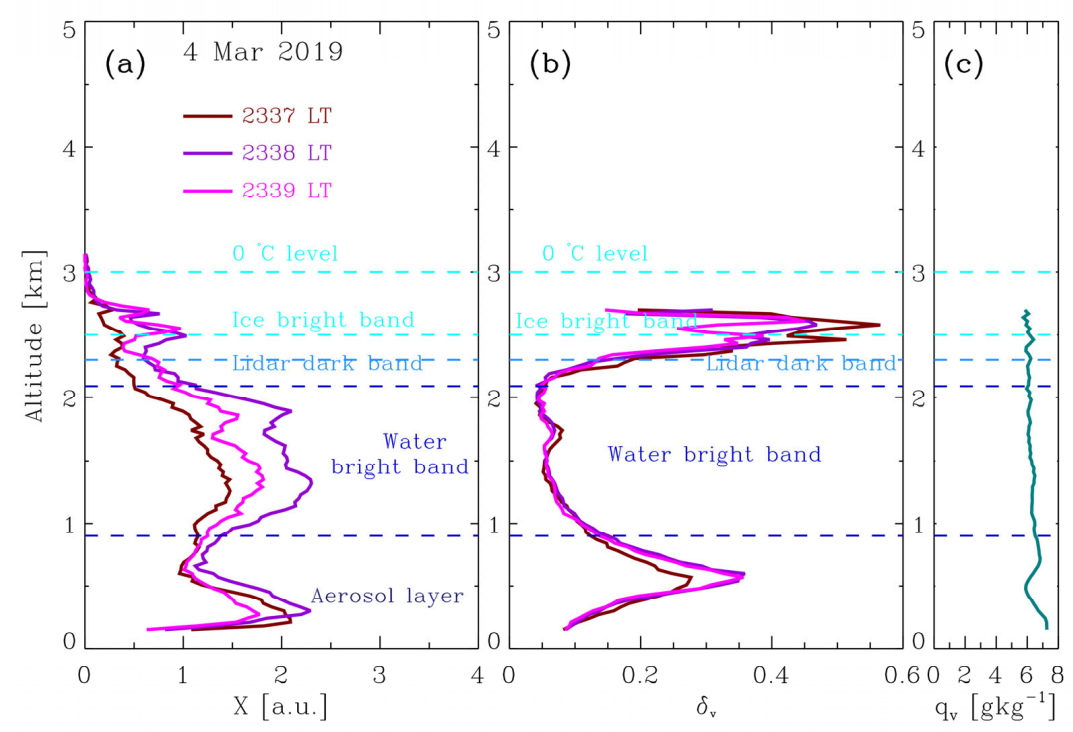

665 Figure 9: Three 1-min lidar $X$ and $\delta$ profiles covering the period from 2337 to 2339 LT on 4 March 2019 and a onehour-averaged lidar $q_{v}$ profile centered at 2338 LT on the same day, exhibiting the vertical structure of the $X$ and $\delta_{v}$ precipitation streaks as well as the water vapor mixing ratio when the surface precipitation rate was highest $(3.2 \mathrm{~mm}$ $h^{-1}$ ) during the studied moderate warm-front precipitation event (yielding thick liquid water accumulation on the roof windows of the lidars; see photo $V$ in Figure 6). 